\title{
The influence of filler type on the separation properties of mixed-matrix membranes
}

\author{
Małgorzata Gnus $^{1}$ (D) Gabriela Dudek ${ }^{1} \cdot$ Roman Turczyn $^{1}$
}

Received: 28 July 2017 / Accepted: 3 December 2017 / Published online: 15 December 2017

(c) The Author(s) 2017. This article is an open access publication

\begin{abstract}
Chitosan-based membranes filled with different metal oxide particles were prepared and their performance in ethanol dehydration process depending on the type of oxide and loading was discussed. For membrane preparation three oxides: $\mathrm{TiO}_{2}$, $\mathrm{Cr}_{2} \mathrm{O}_{3}$ or $\mathrm{Fe}_{3} \mathrm{O}_{4}$ were selected. From experimental data suitable ethanol and water transport coefficients were evaluated. As shown in the results, applied fillers in different ways affect the separation properties. Presence of $\mathrm{TiO}_{2}$ significantly affects the normalized total flux, increasing its value. On the other hand, addition of $\mathrm{Fe}_{3} \mathrm{O}_{4}$ influences most of all the separation factor, which is the among all investigated membranes. For membranes containing chromium(III) oxide as a filler, improvement in the separation properties is observed only in the case when the $\mathrm{Cr}_{2} \mathrm{O}_{3}$ content equals to $5 \mathrm{wt} \%$. Above this concentration significant deterioration of separation properties is observed. The best performance has mixed-matrix membranes (MMMs) with magnetite, where the values of PSI are equal to 16.3 and $296.8 \mathrm{~kg} / \mathrm{m}^{-2} \mathrm{~h} \mu \mathrm{m}$ for pristine and $15 \mathrm{wt} \%$ filler content, respectively.
\end{abstract}

Keywords Pervaporation $\cdot$ Composite membranes $\cdot$ Metal oxides

\section{Introduction}

Membrane separation techniques attract much attention in many fields, since they offer high efficiency with energy savings and have been an environmentally friendly method to deliver the aforementioned properties with the minimal increase in space and weight. Otherwise, pervaporation is, among them, one of the membrane separation techniques applicable for multi-component solutions. Especially, pervaporation is a promising technique for separation of organic liquid mixtures such as azeotropic mixtures (Bolto et al. 2011; Chapman et al. 2008). The success of pervaporation depends mainly on the nature of the polymeric membrane chosen for a particular application in addition to its physical state, structure, chemically interacting groups, addition of filler particles, physicochemical properties of the separated feed mixture, as well as feed component-component and component-membrane interactions (Hussain et al. 1996).

Małgorzata Gnus

malgorzata.gnus@polsl.pl

1 Department of Physical Chemistry and Technology of Polymers, Faculty of Chemistry, Silesian University of Technology, M. Strzody 9 Street, 44-100 Gliwice, Poland
However, the key to success in pervaporation separation lies in the development of a suitable membrane material that offers high flux, good separation factor (selectivity) and long-term stability, and also favourable mechanical strength to withstand the cyclic modes of operating conditions.

Chitosan, as a natural linear biopolyaminosaccharide, is obtained by alkaline deacetylation of chitin and is its most important derivative (Crini and Badot 2008; Dutta et al. 2004). Unfortunately, membranes prepared only with chitosan posed a lack of mechanical strength and stability mainly due to excessive swelling in aqueous solutions. This disadvantage could be overcome by chemical or physical stabilization of membrane structure. The chemical modification of chitosan by using crosslinking reaction offers an alternative pathway for producing chemically more stable chitosan derivatives, which can extend the potential applications of this biopolymer to more areas. The application of chitosan membranes in pervaporation process has played an important role. They have been intensively studied and developed in numerous research groups, and widely used in a plain or modified form Baig 2008; Baker 2004; Chen et al. 2007; Ge et al. 2000; Kang et al. 2013; Lee and Shin 1991; Lee et al. 1992; Sun et al. 2008; Sunitha et al. 2012; Uragami 
and Takigawa 1990; Wu et al. 2016; Yang et al. 2009; Zhang et al. 2007; and Zielinska et al. 2011.

In recent years, the trend has shifted more towards developing filler reinforced matrices as pervaporation membranes (Sun et al. 2008; Yang et al. 2009; Kang et al. 2013; Zhao et al. 2014; Wu et al. 2016). Incorporation of different microor nano-sized materials-metal oxides (Balta et al. 2012; Jiang et al. 2007; Li et al. 2012; Ng et al. 2013; Rybak et al. 2014; Thamaphat et al. 2008; Yang et al. 2009; Zhao et al. 2014), zeolites (Khoonsap and Amnuaypanich 2011; Nigiz and Hilmioglu 2013; Ong et al. 2016; Premakshi et al. 2015; Zhou et al. 2016), silica (Araki et al. 2016, Tancharernrat et al. 2014; Xia et al. 2016)—with polymer matrix, when both of them have different flux and selectivity provides the possibility to obtain synergistic effects and better designing a membrane with desired properties, so hydrophilic polymeric materials filled with the nano-sized fillers could be the ideal materials to selectively separate water from its mixture with an organic component.

In principle, the incorporation of the inorganic component can be seen as a relatively easy modification of existing methods for fabricating large-surface area polymeric membranes. Therefore, mixed-matrix membranes (MMMs) possess an economic advantage over inorganic membranes.

In our previous research (Dudek et al. 2014a, b; Turczyn et al. 2015; Gnus et al. 2015), we investigated chitosan membranes with different addition of iron oxide nanoparticles in the process of ethanol dehydration. The results showed that the addition of particles to chitosan matrix created extra free volumes in polymer, and in consequence, offered space for water molecules to permeate easier through the membranes.

The aim of this work was the comparison between different metal oxide fillers and examination of their influence on the separation properties of chitosan MMMs used for the pervaporative dehydration of ethanol-water solutions.

\section{Theoretical}

For evaluation of the membrane efficiency, several parameters are evaluated. First of all is flux, and it is determined by the amount of permeate collected over a given period of time. The permeation flux $J$ of component $i$ is calculated using the following equation:

$J_{i}=\frac{m_{i}}{A t}\left[\frac{\mathrm{kg}}{\mathrm{m}^{2} \mathrm{~h}}\right]$,

where $m_{i}$ is the weight of component $i$ in permeate [kg], $A$ is the effective membrane area $\left[\mathrm{m}^{2}\right]$, and $t$ is the permeation time $[\mathrm{h}]$.

Flux could be also normalized to the equal thickness of $1 \mu \mathrm{m}$ and calculated as the normalized flux of component $i$ :
$J_{\mathrm{N} i}=\frac{J_{i}}{d}\left[\frac{\mathrm{kg}}{\mathrm{m}^{2} \mathrm{~h} \mu \mathrm{m}}\right]$,

where $d$ is the membrane thickness $[\mu \mathrm{m}]$.

To designate the permeability coefficient, first it was necessary to determine the volume of the individual components in the collected permeate.

$V_{i}=\frac{n_{i} R T}{p_{i}}\left[\mathrm{~m}^{3}\right]$,

where $n_{i}$ is the amount of component $i$ [mol], $R$ is the gas constant, $8.315[\mathrm{~J} / \mathrm{mol} \mathrm{K}], T$ is the temperature of measurement $[\mathrm{K}]$, and $p_{i}$ the partial pressure of component $i[\mathrm{~Pa}]$.

Next, it is necessary to determine the measurable flow of the component $i$ :

$Q_{i}=\frac{V_{i}}{t}\left[\frac{\mathrm{m}^{3}}{\mathrm{~s}}\right]$,

where $V_{i}$ is the volume of component $i\left[\mathrm{~m}^{3}\right]$ and $t$ is the collection time [s].

Then, to make the flow of individual components independent from parameters such as temperature and pressure, it was standardized according to the following equation:

$Q_{\mathrm{STP}}=Q_{i} \frac{T_{\mathrm{STP}} p}{p_{\mathrm{STP}} T} \quad\left[\frac{\mathrm{m}_{\mathrm{STP}}^{3}}{\mathrm{~s}}\right]$,

where $T_{\text {STP }}$ is the standard temperature $298,15 \mathrm{~K}, T$ is the temperature of measurement $[\mathrm{K}], p_{\mathrm{STP}}$ the standard pressure $101,300 \mathrm{~Pa}$, and $p$ is the ambient pressure $[\mathrm{Pa}]$.

In the last step diffusive flux of component $i$ is evaluated:

$J_{\mathrm{D} i}=\frac{Q_{\mathrm{STP}}}{A}\left[\frac{\mathrm{m}_{\mathrm{STP}}^{3}}{\mathrm{~m}^{2} \mathrm{~s}}\right]$,

where $Q_{\mathrm{STP}}$ is the flow in standard conditions $\left[m_{\mathrm{STP}}^{3} / \mathrm{s}\right], A-$ active surface of membrane $\left[\mathrm{m}^{2}\right]$.

Finally, when the diffusive flux and partial vapour pressure of component $i$ in a feed are known, it is possible to estimate the permeability coefficient of component $i$ :

$P_{i}=J_{\mathrm{D} i} \frac{d}{\Delta p}\left[\frac{\mathrm{m}_{\mathrm{STP}}^{3} \mathrm{~m}}{\mathrm{~m}^{2} \mathrm{~s} \mathrm{mmHg}}\right]$,

where $J_{\mathrm{Di}}$ is the diffusive flux of component $i\left[\mathrm{~m}_{\mathrm{STP}}^{3} / \mathrm{m}^{2} \mathrm{~s}\right]$, $d$ is the membrane thickness [m], and $\Delta p$ is the difference between partial vapour of component $i$ in feed and pressure on the permeate side $[\mathrm{mmHg}]$.

Diffusion coefficients of individual components of the mixture were designated by "time lag" method. For evaluation the time delay of component $i$, plot the cumulative dependency 
curves of the component collected mass from the time of the process and designate the tangent to the straight line formed on the curve-corresponding to the established process.

Depending on the initial state, the curve may have a different shape (Fig. 1) and diffusion coefficient could be calculated by two ways using $L_{\mathrm{a}}$ or $L_{\mathrm{b}}$, respectively:

$D_{\mathrm{A} i}=\frac{d^{2}}{6 L_{\mathrm{a}}}\left[\frac{\mathrm{m}^{2}}{\mathrm{~s}}\right]$ or $D_{\mathrm{B} i}=-\frac{d^{2}}{3 L_{\mathrm{b}}}\left[\frac{\mathrm{m}^{2}}{\mathrm{~s}}\right]$,

where $d$ is the membrane thickness [m], $L_{\mathrm{a}}$ and $L_{\mathrm{b}}$ the time lag $[\mathrm{s}]$ determined from the mass versus time graph.

Knowing the permeability and diffusion coefficients, it is possible to estimate the solubility coefficient of component $i$ :

$S_{i}=\frac{P_{i}}{D_{i}}\left[\frac{\mathrm{m}_{\mathrm{STP}}^{3}}{\mathrm{mmHg}}\right]$.

For describing the separation properties of the membrane, separation factor $(\alpha A B)$ was used. Separation factor determines the separation of mixture through the changes of component concentration in the feed and permeate and is calculated by:

$\alpha_{\mathrm{AB}}=\frac{y_{\mathrm{A}} / y_{\mathrm{B}}}{x_{\mathrm{A}} / x_{\mathrm{B}}}$,

where $x_{\mathrm{A}}, x_{\mathrm{B}}$ is the weight fraction of component in the feed [wt $\%$ ], $y_{\mathrm{A}}, y_{\mathrm{B}}$ the weight fraction of components in permeate $[\mathrm{wt} \%]$.

In order to compare the separation efficiency of different investigated membranes, a pervaporation separation index, PSI expressed by following equation is used:

$\mathrm{PSI}=J_{N}\left(\alpha_{\mathrm{AB}}-1\right)\left[\frac{\mathrm{kg}}{\mathrm{m}^{2} \mathrm{~h} \mu \mathrm{m}}\right]$,

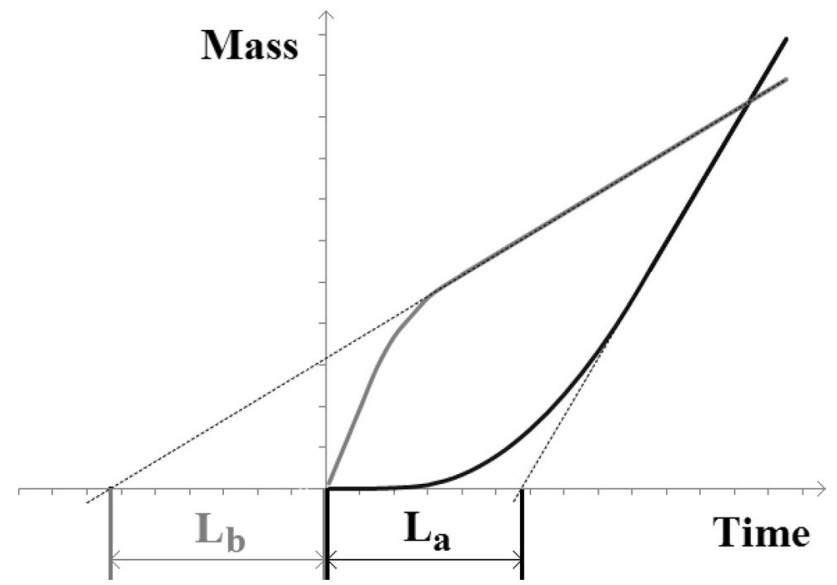

Fig. 1 The methodology of the "time lag" determination. Depending on the initial state of membrane, the curve may have two different shapes and two corresponding time lags $L_{\mathrm{a}}$ or $L_{\mathrm{b}}$ could be derived where $J_{N}$ is the normalized total permeate flux $\left[\mathrm{kg} / \mathrm{m}^{2} \mathrm{~h} \mu \mathrm{m}\right]$, and $\alpha_{\mathrm{AB}}$ is the separation factor.

\section{Experimental}

\section{Chemicals}

Chitosan $\left(M_{\mathrm{n}}=600-800 \mathrm{kDa}\right.$; Acros Organics), iron(II) chloride hexahydrate (pure for analysis, POCh), iron(III) chloride anhydrous (pure, POCh), sodium hydroxide (pure, POCh), 2,2'-(ethylenedioxy)bis(ethylamine) (98\%, Aldrich), $25 \%$ ammonia solution (pure for analysis, Chempur) glycidyl chloride (99\%, Acros Organics), titanium(IV) oxide and chromium(III) oxide (pure, POCh), glacial acetic acid (pure for analysis, POCh).

\section{Preparation of iron(II,III) oxide}

Magnetite was prepared by coprecipitation method. Briefly, $6 \mathrm{~g} \mathrm{FeCl}_{2} \cdot 4 \mathrm{H}_{2} \mathrm{O}$ and $7.4 \mathrm{~g} \mathrm{FeCl}_{3}$ were separate dissolved in bakers containing $40 \mathrm{ml}$ of distilled water. The solutions were combined in larger baker, $5.8 \mathrm{ml}$ of EDBE [2,2'-(ethylenedioxy)bis(ethylamine)] was added and mixed on a magnetic stirrer for about $5 \mathrm{~min}$. Then slowly added $50 \mathrm{ml}$ of $\mathrm{NH}_{3(\text { aq) }}(25 \%)$ and stir for $1 \mathrm{~h}$ until the reaction was completed. After that, baker was placed on a strong magnet to speed up the sedimentation of the resulting magnetite particles and poured out the supernatant. Next, $50 \mathrm{ml}$ of $5 \%$ $\mathrm{NH}_{3(\mathrm{aq})}$ with $5.8 \mathrm{ml}$ of EDBE was added and mixed. The suspension was heated for few minutes, then decantation of obtained powder was used. Then obtained magnetite powder was filtered off and washed with hot distilled water until a negative silver test for the presence of $\mathrm{Cl}^{-}$in filtrate and dried.

\section{Characterization of used particles}

X-ray powder diffraction (XRD) patterns of the samples were recorded on a X-Pert Philips PW 3040/60 diffractometer operating at $30 \mathrm{~mA}$ and $40 \mathrm{kV}$. The radiation wavelength $(\lambda \mathrm{Cu} \mathrm{K} \alpha)$ was $1.54056^{\circ}$. The patterns were recorded in a $2 \theta$ range from $5^{\circ}$ to $110^{\circ}$.

Dynamic light-scattering (DLS) experiments were performed on a particle-size analyzer, model Nano ZS90 (Malvern instruments, UK). All the measurements were carried out at a scattering angle of 90 and a temperature of $25^{\circ} \mathrm{C}$, which was controlled by means of a thermostat. A dilute solution of the sample was prepared by dispersing the powder in ethylene glycol. 


\section{Membranes preparation}

Membranes were prepared by solution casting and solvent evaporation technique. The prepared $3 \mathrm{wt} \%$ chitosan solution in 1 vol\% acetic acid. This solution was mixed with an appropriate portion of metal oxide particles, micro-sized $\mathrm{Cr}_{2} \mathrm{O}_{3}$ as well as nano-sized $\mathrm{TiO}_{2}$ or $\mathrm{Fe}_{3} \mathrm{O}_{4}(5 ; 10 ; 15 \mathrm{wt} \%$ based on the dry weight of the polymer matrix), was casted into a $16 \mathrm{~cm}$ diameter Petri dish and left until solvent evaporation at $40{ }^{\circ} \mathrm{C}$. Next, chitosan membranes were immersed in $0.08 \mathrm{M}$ glycidyl chloride in $2 \%$ sodium hydroxide solution by $24 \mathrm{~h}$ at room temperature. After this time membranes were subsequently washed with distilled water until obtained neutral $\mathrm{pH}$ and dried in room temperature. The pristine chitosan membrane was prepared in the same manner except for the addition of metal oxide filler (see Fig. 2).

The membrane thickness was measured using waterproof precise coating thickness gauge MG-401 ELMETRON, estimated as a mean values of at least 25 measurements.

\section{Pervaporation}

Pervaporation experiments were performed at room temperature on pervaporation setup (Fig. 3). Prepared membrane was placed in a membrane chamber (3) with effective membrane area $10.39 \times 10^{-3} \mathrm{~m}^{2}$. Measurements were performed for membranes in contact with solution containing $96 \mathrm{wt} \%$ of ethanol. Mixture $\left(1 \mathrm{dm}^{3}\right)$ at room temperature was poured into the feed tank (1) and pumped, using a circulation pump (2) with velocity $9.25 \times 10^{-2} \mathrm{~m}^{3} / \mathrm{h}$, to the membrane chamber where feed was separated. Next, retentate was recirculated to the feed tank; however, permeate vapours were condensed in a liquid nitrogen cooled trap (5). Permeate was collected for duration of $7.5 \mathrm{~h}$ and weighed after defrosting on analytical balance to determine the value of total flux. The reduced pressure on the permeate side was 350-390 Pa was produced by a vacuum pump (6) and controlled with a vacuum gauge (4).

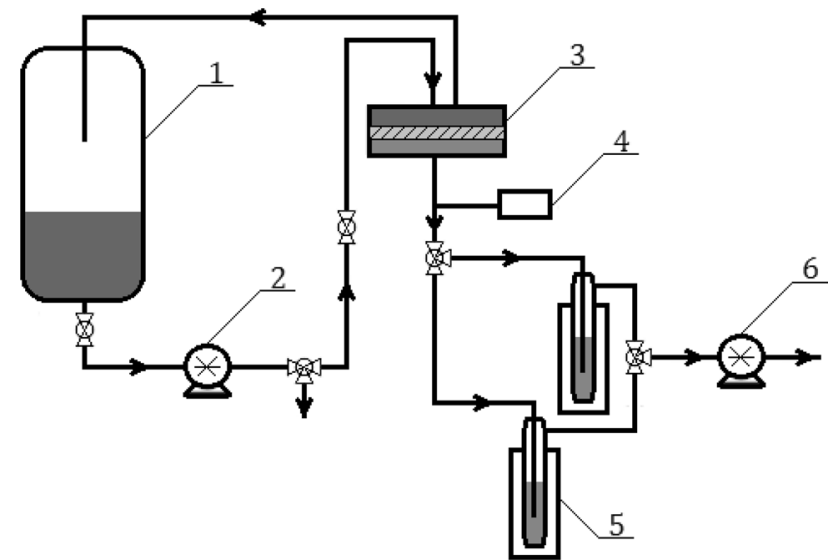

Fig. 3 Scheme of pervaporation setup: 1-feed tank, 2-circulation pump, 3-separation chamber, 4-vacuum gauge, 5-cooled collection traps, 6-vacuum pump

Before measurements, each membrane was conditioned for a few minutes in a membrane chamber being in contact with circulating feed solution and after applying of reduced pressure and its stabilization, flux measurement was started.

The collected samples of permeate as well as feed (before and after process) were analysed by gas chromatography technique. Measurements were performed on a gas chromatograph (Agilent Technologies 6850 Network GC System) equipped with an Elite-WAX ETR column (30 m), and FID detector. Measurements were carried out with nitrogen as carrier gas, with $1 \mu \mathrm{l}$ sample injection and measurement time of $6 \mathrm{~min}$ at constant temperature $-80^{\circ} \mathrm{C}$. The ethanol content was determined on the basis of the prepared calibration curve.

\section{Degree of swelling}

The membrane swelling test in water was determined by weight method. The piece of membrane was weighting before and after their immersion for $24 \mathrm{~h}$ in distilled water or ethanol (96\%). Mass change of analysed membranes
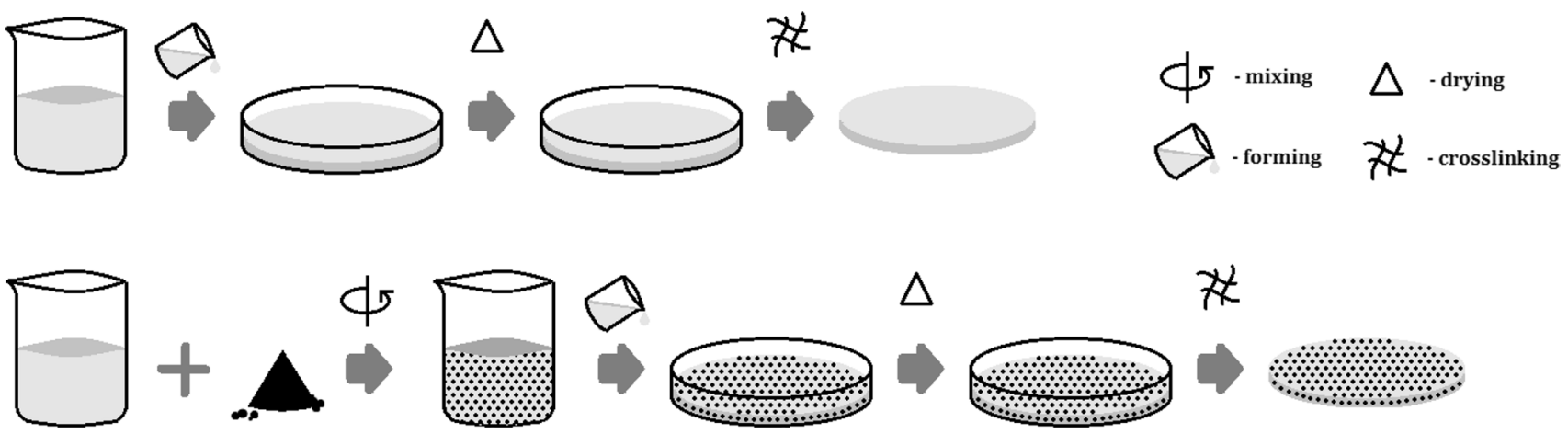

Fig. 2 Scheme of membrane preparation 
was measured using analytical balance and degree of swelling was calculated from following equation:

$\mathrm{DS}=\frac{W_{\mathrm{wet}}-W_{\mathrm{dry}}}{W_{\mathrm{dry}}} \times 100[\%]$,

where $W_{\text {wet }}$ is the weight of the swollen membrane $[\mathrm{g}]$ and $W_{\text {dry }}$ the weight of the dried membrane samples [g].
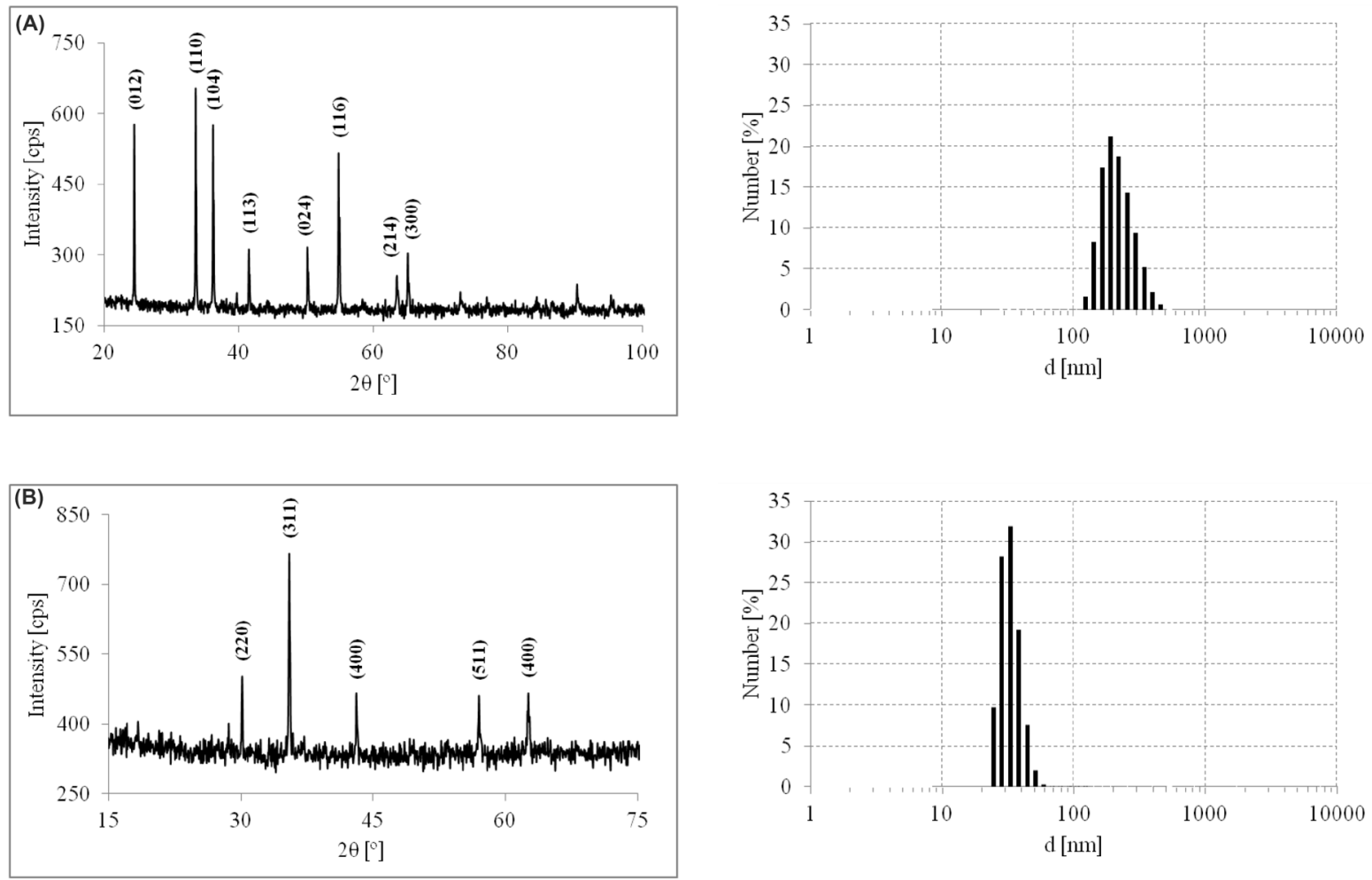

The phase composition and size distribution of used particles were characterized by power X-ray diffraction (XRD) and differential light scattering (DLS), respectively. Figure $4 \mathrm{a}$ shows the XRD pattern of the $\mathrm{Cr}_{2} \mathrm{O}_{3}$. The major peaks were indexed as (012), (110), (104), (113), (024), (214) and (300) which are consistent with references (Farzaneh and Najafi 2011). DLS histogram shows that the grain size is within the $200 \mathrm{~nm}$ limit. Figure $4 \mathrm{~b}$ shows the XRD of the magnetite nanoparticles prepared by coprecipitation method. The observed peaks: (220), (311),

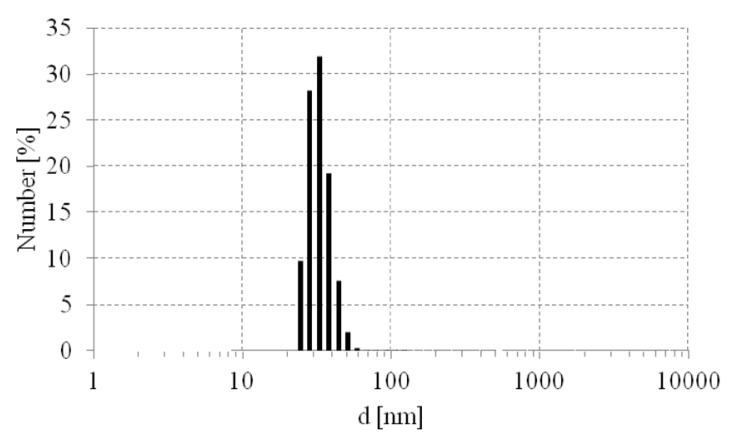

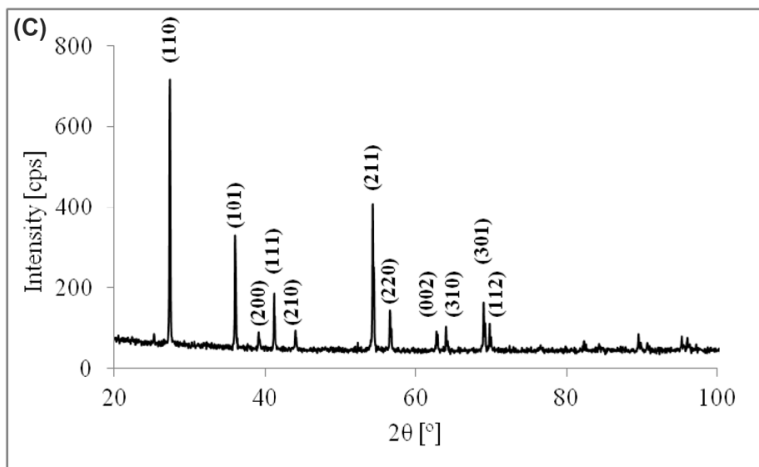

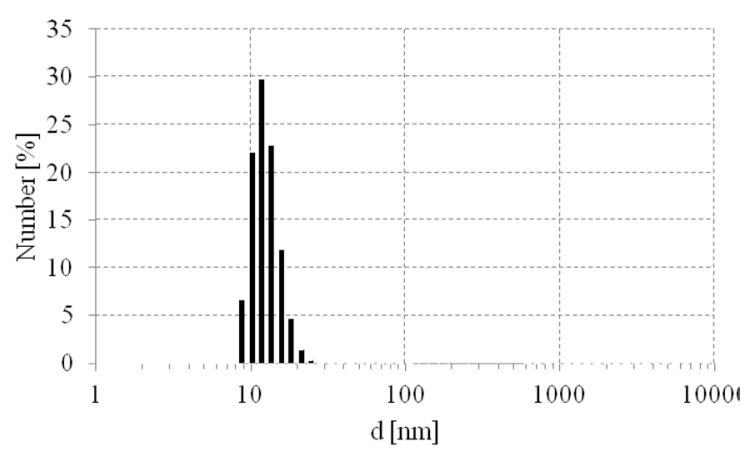

Fig. 4 XRD and DLS analysis of the used particles: $\mathrm{Cr}_{2} \mathrm{O}_{3}(\mathbf{a}), \mathrm{Fe}_{3} \mathrm{O}_{4}(\mathbf{b})$ and $\mathrm{TiO}_{2}$ (c) 
(400), (511) and (400) planes confirm the $\mathrm{Fe}_{3} \mathrm{O}_{4}$ spinel structure (Pati et al. 2012, Han et al. 2014). According to DLS measurement, the grain size is within the $25-50 \mathrm{~nm}$ range. The $\mathrm{TiO}_{2}$ was confirmed by presence of peaks: (110), (101), (200), (111), (220), (002), (310), (301) and (112) planes corresponding to rutile phase (Fig. 4c), but $\mathrm{X}$-ray line shape could suggest that it has micro-sized grains (Thamaphat et al. 2008). On the other hand, DLS measurement shows that particles hydrodynamic diameter was $9-12 \mathrm{~nm}$. This is probably due to the good stability of dispersion in ethylene glycol particles, which limits aggregation of $\mathrm{TiO}_{2}$ particles.

The evaluated parameters for pervaporation process describing transport properties, i.e. diffusion, permeation and solubility coefficients of ethanol and water through both, pristine and composite epichlorohydrin-crosslinked chitosan membranes are collected in Table 1.

The results showed that the evaluated values of diffusion coefficient differ for water and ethanol permeating through epichlorohydrin-crosslinked chitosan MMMs. Both, pristine epichlorohydrin-crosslinked chitosan membranes and membranes contained $\mathrm{Cr}_{2} \mathrm{O}_{3}$ and $\mathrm{TiO}_{2}$, reach much higher value of ethanol diffusion coefficient than for water. Otherwise, for membranes with $\mathrm{Fe}_{3} \mathrm{O}_{4}$ filler the reverse trend in diffusion coefficient was observed.

The addition of iron(II,III) oxide particles influenced both the diffusion and solubility coefficients of water and ethanol. Magnetite presence invoked increasing of water diffusion coefficient and decreasing of ethanol diffusion coefficient in comparison to pristine membrane. Additionally, increasing content of filler influenced further decrease of ethanol diffusion coefficient from $70.1 \times 10^{-14}$ to $22.7 \times 10^{-14} \mathrm{~m}^{2} / \mathrm{s}$, but increased ethanol solubility from $8.80 \mathrm{~m}_{\mathrm{STP}}^{3} / \mathrm{m}^{2} / \mathrm{m} \mathrm{mmHg}$ to $21.10 \mathrm{~m}_{\mathrm{STP}}^{3} / \mathrm{m}^{2} / \mathrm{m} \mathrm{mmHg}$. Despite increasing ethanol solubility with higher amount of magnetite, their values are 3.5 times lower than for water, which in effect better penetrate into membrane. Presence of $\mathrm{Fe}_{3} \mathrm{O}_{4}$ particles makes membrane less susceptible to swelling in water which causes a decrease their permeation across the membrane and the observed values of water permeation coefficient decreased.

For pristine chitosan membrane the diffusion coefficients for water and ethanol were equal $8.9 \times 10^{-14}$ and $131.2 \times 10^{-14} \mathrm{~m}^{2} / \mathrm{s}$, respectively. The addition of $\mathrm{Cr}_{2} \mathrm{O}_{3}$ particles into chitosan matrix increased the diffusion coefficient of both feed's components, i.e. 4.5 and 3.5 times for water and ethanol, respectively. Addition of hydrophilic $\mathrm{Cr}_{2} \mathrm{O}_{3}$ increased the membrane hydrophilicity and increased water transport across this membrane was observed. Furthermore, greater amount of filler creates an extra free volume in polymer matrix, and in consequence, offers more space for permeating both water and ethanol molecules. The highest content of $\mathrm{Cr}_{2} \mathrm{O}_{3}(15 \mathrm{wt} \%)$ influences increase of water solubility coefficient and ethanol diffusion coefficient, although decreases the ethanol solubility coefficient and water diffusion coefficient.

When polymer matrix contained $\mathrm{TiO}_{2}$, decrease of ethanol diffusion coefficient from $131.2 \times 10^{-14}$ to $99.7 \times 10^{-14}$ $\mathrm{m}^{2} / \mathrm{s}$ and considerable increase of water diffusion coefficient from $8.9 \times 10^{-14}$ to $47.3 \times 10^{-14} \mathrm{~m}^{2} / \mathrm{s}$ were observed; however, contrary trend of solubility coefficient, i.e. increase of ethanol and decrease of water solubility coefficient were observed. Further addition of $\mathrm{TiO}_{2}$ increases both water and ethanol permeation coefficient and decrease their diffusion coefficients, whereas $15 \mathrm{wt} \% \mathrm{TiO}_{2}$ has influence on increase diffusion coefficients and decrease solubility coefficients for water and ethanol molecules.

Despite the created free volumes, for $15 \mathrm{wt} \% \mathrm{Cr}_{2} \mathrm{O}_{3}$ loaded membrane permeation coefficient for both, water and ethanol decrease in similar manner to the membrane containing $15 \mathrm{wt} \%$ of $\mathrm{TiO}_{2}$ particles.

The presence of titanium(IV) oxide mainly affected ethanol transport rather than water. Addition of hydrophilic filler raised the membrane hydrophilic character and reduced a membrane affinity to organic solvent. Unfortunately, higher content of this filler caused mostly increasing of ethanol content in permeate rather than water.

Table 1 Evaluated transport parameters of water and ethanol of epichlorohydrin-crosslinked chitosan membranes without and with different amount of inorganic fillers

\begin{tabular}{|c|c|c|c|c|c|c|c|c|c|c|}
\hline \multirow{2}{*}{$\begin{array}{l}\text { Membrane } \\
\text { Filler content [wt } \%]\end{array}$} & \multirow{2}{*}{$\begin{array}{l}\mathrm{CS} \\
0\end{array}$} & \multicolumn{3}{|c|}{ CS_Cr $r_{2} \mathrm{O}_{3}$} & \multicolumn{3}{|c|}{$\mathrm{CS} \_\mathrm{Fe}_{3} \mathrm{O}_{4}$} & \multicolumn{3}{|c|}{ CS_TiO 2} \\
\hline & & 5 & 10 & 15 & 5 & 10 & 15 & 5 & 10 & 15 \\
\hline \multicolumn{11}{|l|}{ Water } \\
\hline Diffusion coefficient, $D \times 10^{14}\left[\mathrm{~m}^{2} / \mathrm{s}\right]$ & 8.9 & 37.2 & 20.1 & 4.4 & 101.2 & 162.4 & 39.8 & 47.3 & 6.7 & 13.4 \\
\hline Permeation coefficient, $P \times 10^{12}\left[\mathrm{~m}_{\mathrm{STP}}^{3} \mathrm{~m} / \mathrm{m}^{2} \mathrm{mmHg} \mathrm{s}\right]$ & 34.9 & 44.5 & 38.3 & 37.2 & 28.5 & 32.0 & 31.1 & 35.4 & 45.1 & 31.9 \\
\hline Solubility coefficient, $S\left[\mathrm{~m}_{\mathrm{STP}}^{3} / \mathrm{m} \mathrm{mmHg}\right]$ & 392.25 & 119.60 & 190.60 & 884.77 & 28.19 & 19.69 & 78.19 & 74.82 & 673.28 & 238.13 \\
\hline \multicolumn{11}{|l|}{ Ethanol } \\
\hline Diffusion coefficient, $D \times 10^{14}\left[\mathrm{~m}^{2} / \mathrm{s}\right]$ & 131.2 & 464.1 & 58.7 & 67.4 & 70.1 & 50.7 & 22.7 & 99.7 & 38.3 & 506.4 \\
\hline Permeation coefficient, $P \times 10^{12}\left[\mathrm{~m}_{\mathrm{STP}}^{3} \mathrm{~m} / \mathrm{m}^{2} \mathrm{mmHg} \mathrm{s}\right]$ & 5.2 & 2.7 & 9.4 & 4.5 & 6.2 & 6.8 & 4.8 & 4.8 & 7.8 & 7.1 \\
\hline Solubility coefficient, $S\left[\mathrm{~m}_{\mathrm{STP}}^{3} / \mathrm{m} \mathrm{mmHg}\right]$ & 3.95 & 0.58 & 16.03 & 6.60 & 8.80 & 13.33 & 21.10 & 4.83 & 20.26 & 1.41 \\
\hline
\end{tabular}


Table 2 Degree of swelling in distilled water and pure ethanol $(99.8 \%)$ measured for pristine epichlorohydrin-crosslinked chitosan membranes and with different oxide filler

\begin{tabular}{|c|c|c|c|c|c|c|c|c|c|c|}
\hline \multirow{2}{*}{$\begin{array}{l}\text { Membrane } \\
\text { Filler content [wt } \%]\end{array}$} & \multirow{2}{*}{$\begin{array}{l}\text { CS } \\
0\end{array}$} & \multicolumn{3}{|c|}{ CS_Cr ${ }_{2} \mathrm{O}_{3}$} & \multicolumn{3}{|c|}{$\mathrm{CS} \_\mathrm{Fe}_{3} \mathrm{O}_{4}$} & \multicolumn{3}{|c|}{$\mathrm{CS}_{-} \mathrm{TiO}_{2}$} \\
\hline & & 5 & 10 & 15 & 5 & 10 & 15 & 5 & 10 & 15 \\
\hline Degree of swelling in water [\%] & 108.6 & 94.9 & 92.7 & 121.5 & 103.9 & 95.2 & 89.9 & 105.4 & 111.1 & 96.7 \\
\hline Degree of swelling in ethanol [\%] & 4.3 & 5.8 & 1.1 & 0.8 & 1.6 & 3.5 & 2.8 & 5.2 & 6.2 & 0.8 \\
\hline
\end{tabular}

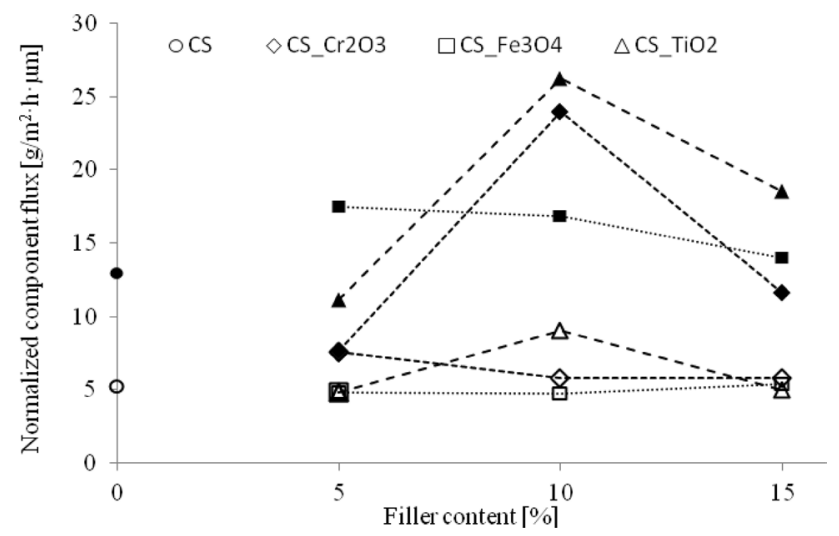

Fig. 5 Normalized component's fluxes for pristine and composite epichlorohydrin-crosslinked chitosan MMMs (filled marks—ethanol, blank marks-water)

This phenomenon can be explained by the fact that the addition of $\mathrm{TiO}_{2}$ nanoparticles to the chitosan matrix created extra free volumes in polymer, and in consequence, offered space for easier permeation of water molecules through membrane. When filer content was $15 \mathrm{wt} \%$, both ethanol and water fluxes decreased. Similar remarks was observed by Sarinam et al. (2006), where $\mathrm{TiO}_{2}$ particles at high content in the PVA matrix will act as the reinforcing bridge elements, thus making the PVA chains more tighter, thereby giving a reduced swelling effect in water and ethanol (Table 2) with the simultaneous decrease in flux at higher amount of $\mathrm{TiO}_{2}$ (Fig. 5).

Addition of $5 \mathrm{wt} \% \mathrm{Cr}_{2} \mathrm{O}_{3}$ to chitosan membrane caused increasing water and decreasing ethanol normalized flux in comparison to membrane without filler. Higher content of $\mathrm{Cr}_{2} \mathrm{O}_{3}$, analogical as for $\mathrm{TiO}_{2}$, made more free volume available in membrane and implied higher ethanol normalized flux. Further decreasing of ethanol normalized flux was observed above this content of $\mathrm{Cr}_{2} \mathrm{O}_{3}$, when degree of swelling in water significantly increased and membrane affinity toward ethanol is decreasing.

When $5 \mathrm{wt} \%$ of $\mathrm{Fe}_{3} \mathrm{O}_{4}$ was added to the pristine membrane, normalized flux of ethanol increased, but the future filler implementation results in a gradual decrease of ethanol normalized flux. On the other hand, normalized flux of water increased, despite decreased degree of swelling in water, if the content of magnetite in MMMs is increasing. At the beginning addition of $\mathrm{Fe}_{3} \mathrm{O}_{4}$ particles to the MMMs caused an increase of free volume in polymer matrix, but despite the future increase of filler amount, the determined value of a total flux did not increase. This is probably related to the magnetic properties of $\mathrm{Fe}_{3} \mathrm{O}_{4}$-higher amount generate stronger magnetic field, which has beneficial influence on the membrane separation properties constituting a barrier for ethanol molecules while facilitating the transport of water molecules across the membrane. Magnetite, as a filler, affects the composition of the permeate-increasing water and decreasing ethanol normalized fluxes, but not influencing the value of total normalized flux, in effect improve in this way the separation factor of these membranes.

In order to compare the separation efficiency of different investigated membranes, pervaporation separation index was used (Table 3). It can be seen that different metal oxides influence the membrane properties in different ways. Titanium(IV) oxide has a major influence on normalize total flux. Unfortunately, presence of $\mathrm{TiO}_{2}$ influence rather on the ethanol flux, which is higher when membrane contained above $5 \mathrm{wt} \%$ filler, in effect their separation factor is not impressive. On the other hand, iron(II,III) oxide has influence more on separation factor than on the total normalized flux. Separation factor for membrane containing 15 wt $\% \mathrm{Fe}_{3} \mathrm{O}_{4}$ was equal to 16.3 and was about eight times higher than for pristine membrane. Chromium(III) oxide influence on both transport parameters, but filler content level above $10 \mathrm{wt} \%$ results in the deterioration of transport
Table 3 Comparison of pervaporation separation index, PSI for all studied chitosan MMMs

\begin{tabular}{|c|c|c|c|c|c|c|c|c|c|c|}
\hline \multirow{2}{*}{$\begin{array}{l}\text { Membrane } \\
\text { Filler content [wt } \%]\end{array}$} & \multirow{2}{*}{$\begin{array}{l}\text { CS } \\
0\end{array}$} & \multicolumn{3}{|c|}{ CS_Cr ${ }_{2} \mathrm{O}_{3}$} & \multicolumn{3}{|c|}{$\mathrm{CS} \_\mathrm{Fe}_{3} \mathrm{O}_{4}$} & \multicolumn{3}{|c|}{ CS_TiO ${ }_{2}$} \\
\hline & & 5 & 10 & 15 & 5 & 10 & 15 & 5 & 10 & 15 \\
\hline $\begin{array}{l}\text { Normalized total flux, } \\
J_{N} \times 10^{3}\left[\mathrm{~kg} / \mathrm{m}^{2} \mathrm{~h} \mu \mathrm{m}\right]\end{array}$ & 18.1 & 15.2 & 29.8 & 17.4 & 22.3 & 21.5 & 19.4 & 16.0 & 35.3 & 23.5 \\
\hline Separation factor, $\alpha_{\mathrm{AB}}[-]$ & 1.9 & 9.7 & 3.8 & 1.3 & 4.4 & 4.7 & 16.3 & 1.6 & 1.5 & 1.5 \\
\hline $\begin{array}{l}\text { Pervaporative separation index, } \\
\text { PSI } \times 10^{3}\left[\mathrm{~kg} / \mathrm{m}^{2} \mathrm{~h} \mu \mathrm{m}\right]\end{array}$ & 16.3 & 132.2 & 83.4 & 5.2 & 75.8 & 79.6 & 296.8 & 9.6 & 17.7 & 11.8 \\
\hline
\end{tabular}


Table 4 Comparsion of pervaporation performance of chitosan-based membranes for dehydration of ethanol aqueous solution

\begin{tabular}{|c|c|c|c|c|c|c|c|}
\hline Polymer matrix & Filler/content (wt $\%)$ & Cross-linking agent & $\begin{array}{l}\text { Ethanol in } \\
\text { feed (wt } \%)\end{array}$ & Temp $\left({ }^{\circ} \mathrm{C}\right)$ & Flux $\left(\mathrm{kg} / \mathrm{m}^{2} \mathrm{~h}\right)$ & $\begin{array}{l}\text { Separation } \\
\text { factor } \alpha(-)\end{array}$ & References \\
\hline Chitosan & - & - & 96 & 40 & 0.007 & 202 & $\begin{array}{l}\text { (Uragami and Takigawa } \\
\text { 1990) }\end{array}$ \\
\hline Chitosan & - & - & 85 & 50 & 0.275 & 200 & (Chen et al. 2007) \\
\hline Chitosan & - & - & 90 & 30 & 0.037 & 41 & (Zielinska et al. 2011) \\
\hline Chitosan & - & - & 90 & 80 & 0.054 & 158.02 & (Sun et al. 2008) \\
\hline Chitosan acetate salt & - & - & 96 & 40 & 0.002 & 2556 & $\begin{array}{l}\text { (Uragami and Takigawa } \\
\text { 1990) }\end{array}$ \\
\hline Chitosan acetate salt & - & - & 90 & 25 & 0.142 & 242 & $\begin{array}{l}\text { (Lee and Shin 1991; Lee } \\
\text { 1993) }\end{array}$ \\
\hline Chitosan & - & GA & 96 & 40 & 0.004 & 2208 & $\begin{array}{l}\text { (Uragami and Takigawa } \\
\text { 1990) }\end{array}$ \\
\hline Chitosan & - & GA & 90 & 50 & 0.201 & 127 & (Zhang et al. 2007) \\
\hline Chitosan & - & GA & 90 & 60 & 0.250 & 105 & (Zhang et al. 2007) \\
\hline Chitosan & - & GA & 90 & 30 & 0.051 & 27 & (Zielinska et al. 2011) \\
\hline Chitosan & - & SA & 90 & 60 & 0.472 & 1791 & (Ge et al. 2000) \\
\hline Chitosan & - & PA & 95.58 & & 0.58 & 213 & (Sunitha et al. 2012) \\
\hline Chitosan & $8 \% \mathrm{H}-\mathrm{ZSM}-5$ & - & 90 & 80 & 0.231 & 152.82 & (Sun et al. 2008) \\
\hline Chitosan & $6 \% \mathrm{TiO}_{2}$ & - & 90 & 80 & 0.340 & 196 & (Yang et al. 2009) \\
\hline Chitosan & $6 \%$ ZIF-7 & GA & 90 & 25 & 0.337 & 2368 & (Kang et al. 2013) \\
\hline Chitosan & $30 \% \mathrm{~PB}^{\mathrm{a}}$ & GA & 90 & 25 & 0.650 & 1500 & (Wu et al. 2016) \\
\hline Phosphorylated chitosan & - & - & 90 & 70 & 0.180 & 541 & $\begin{array}{l}\text { (Lee and Shin 1991; Lee } \\
\text { 1993) }\end{array}$ \\
\hline $\begin{array}{l}\text { Chitosan/3-aminopro- } \\
\text { pyl-triethoxysilane } \\
(10 \%)\end{array}$ & - & - & 85 & 50 & 0.887 & 597 & (Chen et al. 2007) \\
\hline $\begin{array}{l}\text { Carboxymethylated } \\
\text { chitosan }\end{array}$ & - & - & 90 & 25 & 0.036 & 1294 & $\begin{array}{l}\text { (Lee and Shin 1991, Lee } \\
\text { 1993) }\end{array}$ \\
\hline $\begin{array}{l}\text { Carboxyethylated } \\
\text { chitosan }\end{array}$ & - & - & 90 & 25 & 0.030 & 301 & $\begin{array}{l}\text { (Lee and Shin 1991; Lee } \\
\text { 1993) }\end{array}$ \\
\hline Cyanoethylated chitosan & - & - & 90 & 25 & 0.080 & 52 & $\begin{array}{l}\text { (Lee and Shin 1991; Lee } \\
\text { 1993) }\end{array}$ \\
\hline Sulphonated chitosan & - & GA & 90 & 25 & 0.052 & 1560 & $\begin{array}{l}\text { (Lee and Shin 1991; Lee } \\
\text { 1993) }\end{array}$ \\
\hline Carboxylated chitosan & - & GA/MA & 90 & 50 & 0.238 & 991 & (Zhang et al. 2007) \\
\hline Carboxylated chitosan & - & GA/MA & 90 & 60 & 0.300 & 634 & (Zhang et al. 2007) \\
\hline $\begin{array}{l}\text { Chitosan/hydroxyethyl- } \\
\text { cellulose }(3: 1)\end{array}$ & - & UFSA & 90 & 60 & 0.112 & 10.491 & (Chanachai et al. 2000) \\
\hline $\begin{array}{l}\text { Chitosan/sodium } \\
\text { alginate }\end{array}$ & - & - & 95 & & 0.070 & 1110 & (Moon et al. 1999) \\
\hline $\begin{array}{l}\text { Chitosan/sodium } \\
\text { alginate }\end{array}$ & - & - & 86,4 & & 0.220 & 436 & (Kanti et al. 2004) \\
\hline PVA/chitosan (60/40) & - & GA & 90 & 60 & 0.47 & 450 & (Lee et al. 1992) \\
\hline Chitosan & - & $\mathrm{ECH}$ & 96 & 25 & 1.036 & 1.9 & Present work \\
\hline Chitosan & $5 \% \mathrm{Cr}_{2} \mathrm{O}_{3}$ & $\mathrm{ECH}$ & 96 & 25 & 0.848 & 9.7 & Present work \\
\hline Chitosan & $10 \% \mathrm{Cr}_{2} \mathrm{O}_{3}$ & $\mathrm{ECH}$ & 96 & 25 & 1.739 & 3.8 & Present work \\
\hline Chitosan & $15 \% \mathrm{Cr}_{2} \mathrm{O}_{3}$ & $\mathrm{ECH}$ & 96 & 25 & 0.958 & 1.3 & Present work \\
\hline Chitosan & $5 \% \mathrm{TiO}_{2}$ & $\mathrm{ECH}$ & 96 & 25 & 0.878 & 1.6 & Present work \\
\hline Chitosan & $10 \% \mathrm{TiO}_{2}$ & $\mathrm{ECH}$ & 96 & 25 & 1.456 & 1.5 & Present work \\
\hline Chitosan & $15 \% \mathrm{TiO}_{2}$ & $\mathrm{ECH}$ & 96 & 25 & 1.251 & 1.5 & Present work \\
\hline Chitosan & $5 \% \mathrm{Fe}_{3} \mathrm{O}_{4}$ & $\mathrm{ECH}$ & 96 & 25 & 1.111 & 4.4 & Present work \\
\hline Chitosan & $10 \% \mathrm{Fe}_{3} \mathrm{O}_{4}$ & $\mathrm{ECH}$ & 96 & 25 & 1.070 & 4.7 & Present work \\
\hline Chitosan & $15 \% \mathrm{Fe}_{3} \mathrm{O}_{4}$ & $\mathrm{ECH}$ & 96 & 25 & 0.845 & 16.3 & Present work \\
\hline
\end{tabular}

$G A$ glutaraldehyde, GA/MA glutaraldehyde and maleic anhydride, $S A$ sulfuric acid (VI), $P A$ phosphoric acid (V), $F$ formaldehyde, $E C H$ epichlorohydrin, UFSA crosslinking bath containing: urea, formaldehyde and sulfuric acid (VI)

${ }^{\text {a}}$ Prussian blue 
characteristics with respect to the pristine membrane. The highest values of pervaporation separation index were obtained for membranes containing $15 \mathrm{wt} \% \mathrm{Fe}_{3} \mathrm{O}_{4}(296.8 \mathrm{~kg} /$ $\left.\mathrm{m}^{2} \mathrm{~h} \mu \mathrm{m}\right), 5 \mathrm{wt} \% \mathrm{Cr}_{2} \mathrm{O}_{3}\left(132.2 \mathrm{~kg} / \mathrm{m}^{2} \cdot \mathrm{h} \mu \mathrm{m}\right), 10 \mathrm{wt} \% \mathrm{Cr}_{2} \mathrm{O}_{3}$ $\left(83.4 \mathrm{~kg} / \mathrm{m}^{2} \mathrm{~h} \mathrm{\mu m}\right), 10 \mathrm{wt} \% \mathrm{Fe}_{3} \mathrm{O}_{4}$ and $5 \mathrm{wt} \% \mathrm{Fe}_{3} \mathrm{O}_{4}(79.6$ and $75.8 \mathrm{~kg} / \mathrm{m}^{2} \mathrm{~h} \mu \mathrm{m}$, respectively).

\section{Comparsion of pervaporation performance of chitosan-based hybrid membranes}

Chitosan, as a biopolymer, is widely used as a membrane material for pervaporation dehydration of organic-aqueous solutions due to its outstanding selectivity toward water, adhesiveness, film-forming ability, and resistance to organic solvents. Table 4 summarizes the pervaporation performance of chitosan-based homogenous as well as hybrid membranes for the dehydration of ethanol solution reported in the literature. It could be seen that there was a relationship between the flux and the separation factor. Unfortunately, it was very rare to have a high efficiency of the process at high flux values, on the other hand low value of obtained flux made impossible to use this type of membrane on an industrial scale. However, very important factors in the pervaporative dehydration process were temperature and the feed concentration.

Changes in the composition of the feed significantly affect the efficiency of the process using hydrophilic membranes, since lowering the water content reduces the possibility of swelling of the membranes and decreasing of permeation flux. Won et al. (1996) studied the influence of feed composition on water transport across pristine chitosan membranes in pervaporation process at $40{ }^{\circ} \mathrm{C}$. They noticed, that the higher concentration of water in separation mixture influences on the increasing of obtained permeation flux. Additionally, the content of water in permeate was not linear. Additionally, increasing the feed temperature also has a positive influence on permeation flux, whereas decreased the separation factor (Jiraratananon et al. 2002).

Membranes prepared in this work are characterized by quite high values of permeation fluxes with much lower values of separation factor than other mixed-matrix membranes presented in literature; however, addition of inorganic filler could improve membrane properties. Furthermore, knowledge on the effect of the type and amount of fill will allow to design new, more efficient membranes for pervaporative dehydration processes.

\section{Conclusions}

In this paper was discussed the influence of filler type and amount presence on the epichlorohydrin-crosslinked chitosan membrane's water/ethanol separation properties.
In pervaporation experiments as polymer matrix fillers were used particles like $\mathrm{Cr}_{2} \mathrm{O}_{3}, \mathrm{TiO}_{2}$ and $\mathrm{Fe}_{3} \mathrm{O}_{4}$ content ranged from 5 to $15 \mathrm{wt} \%$. Each filler influences membrane properties in different ways. Magnetite, as a filler affects separation factor and normalized total flux increasing their values. Titanium(IV) oxide affects mainly total normalized flux, but does not change their separation properties, whereas membranes containing chromium(III) oxide influences both, separation factor and normalized total flux.

Comparing the separation properties it can be concluded that the epichlorohydrin-crosslinked chitosan membranes containing iron(II,III) oxide have better separation properties than the corresponding pristine and other prepared membranes. The best separation parameters were obtained for epichlorohydrin-crosslinked chitosan membrane containing 15 wt $\% \mathrm{Fe}_{3} \mathrm{O}_{4}$ and $5 \mathrm{wt} \% \mathrm{Cr}_{2} \mathrm{O}_{3}$, while membranes containing $\mathrm{TiO}_{2}$ had worse properties than pristine membrane.

Acknowledgements The authors would like to thank the Silesian University of Technology for providing financial support under the project BKM-526/RCH4/2016.

Open Access This article is distributed under the terms of the Creative Commons Attribution 4.0 International License (http://creativecommons.org/licenses/by/4.0/), which permits unrestricted use, distribution, and reproduction in any medium, provided you give appropriate credit to the original author(s) and the source, provide a link to the Creative Commons license, and indicate if changes were made.

\section{References}

Araki S, Gondo D, Imasaka S, Yamamoto H (2016) Permeation properties of organic compounds from aqueous solutions through hydrophobic silica membranes with different functional groups by pervaporation. J Membr Sci 514:458-466. https://doi.org/10.1016/j. memsci.2016.04.075

Baig FU (2008) Pervaporation. In: Li NN, Fane AG, Ho WSW, Matsuura T (eds) Advanced membrane technology and applications. Wiley, Hoboken

Baker RW (2004) Membrane technology and applications. Wiley, New York

Balta S, Sotto A, Luis P, Benea L, Van Der Bruggen B, Kim J (2012) A new outlook on membrane enhancement with nanoparticles: the alternative of ZnO. J Membr Sci 389:155-161. https://doi. org/10.1016/j.memsci.2011.10.025

Bolto B, Hoang M, Xie Z (2011) A review of membrane selection for the dehydration of aqueous ethanol by pervaporation. Chem Eng Process 50:227-235. https://doi.org/10.1016/j.cep.2011.01.003

Chanachai A, Jiraratananon R, Uttapap D, Moon GY, Anderson WA, Huang RYM (2000) Pervaporation with chitosan/hydroxyethylcellulose (CS/HEC) blended membranes. J Membr Sci 166:271-280. https://doi.org/10.1016/S0376-7388(99)00269-0

Chapman PD, Oliviera T, Livingston AG, Li K (2008) Membranes for the dehydration of solvents by pervaporation. J Membr Sci 318:5-37. https://doi.org/10.1016/j.memsci.2008.02.061

Chen JH, Liu QL, Zhang XH, Zhang QG (2007) Pervaporation and characterisation of chitosan membranes cross-linked by 
3-aminopropyltriethoxysilane. J Membr Sci 292:125-132. https:// doi.org/10.1016/j.memsci.2007.01.026

Crini C, Badot PM (2008) Application of chitosan, a natural aminopolysaccharide, for dye removal from aqueous solutions by adsorption processes using batch studies: a review of recent literature. Prog Polym Sci 33:399-447. https://doi.org/10.1016/j. progpolymsci.2007.11.001

Dudek G, Gnus M, Turczyn R, Strzelewicz A, Krasowska M (2014a) Pervaporation with chitosan membranes containing iron oxide nanoparticles. Sep Purif Technol 133:8-15. https://doi. org/10.1016/j.seppur.2014.06.032

Dudek G, Strzelewicz A, Turczyn R (2014b) The study of ethanol/ water vapors permeation through sulfuric acid cross-linked chitosan magnetic membranes. Sep Sci Technol 49:1761-1767. https://doi.org/10.1080/01496395.2014.906455

Dutta PK, Dutta J, Tripathi VS (2004) Chitin and chitosan: chemistry, properties and applications. J Sci Ind Res 63:20-31

Farzaneh F, Najafi M (2011) Synthesis and Characterization of $\mathrm{Cr}_{2} \mathrm{O}_{3}$ Nanoparticles with Triethanolamine in Water under Microwave Irradiation. J Sci Islam Repub Iran 22:329-333. https://doi. org/10.22059/jsciences.2011.23867

Ge J, Cui Y, Yan Y, Jiang W (2000) The effect of structure on pervaporation of chitosan membrane. J Membr Sci 165:75-81. https://doi. org/10.1016/S0376-7388(99)00228-8

Gnus M, Dudek G, Turczyn R, Tórz A, Łącka D, Konieczny K, Łapkowski M (2015) Pervaporative investigation of ethyl alcohol dehydration. PCACD 20:54-63. https://doi.org/10.15259/ PCACD.20.05

Han R, Li W, Pan W, Zhu M, Zhou D, Li F-S (2014) 1D magnetic materials of $\mathrm{Fe}_{3} \mathrm{O}_{4}$ and $\mathrm{Fe}$ with high performance of microwave absorption fabricated by electrospinning method. Sci Rep 4:7493. https://doi.org/10.1038/srep07493

Hussain M, Nakahira A, Nishijima S, Niihara K (1996) Fracture behavior and fracture toughness of particulate filled epoxy composites. Mater Lett 27:21-25. https://doi. org/10.1016/0167-577X(95)00254-5

Jiang LY, Shung T, Rajagopalan R (2007) Matrimid/MgO mixed matrix membranes for pervaporation. AIChE J 53:1745. https:// doi.org/10.1002/aic.11198

Jiraratananon R, Chanachai A, Huang RYM, Uttapap D (2002) Pervaporation dehydration of ethanol-water mixtures with chitosan/ hydroxyethylcellulose (CS/HEC) composite membranes I. Effect of operating conditions. J Membr Sci 195:143-151. https://doi. org/10.1016/S0376-7388(01)00563-4

Kang C-H, Lin Y-F, Huang Y-S, Tung K-L, Chang K-S, Chen J-T, Hung W-S, Lee K-R, Lai J-Y (2013) Synthesis of ZIF-7/chitosan mixed-matrix membranes with improved separation performance of water/ethanol mixtures. J Membr Sci 438:105-111. https://doi. org/10.1016/j.memsci.2013.03.028

Kanti P, Srigowri K, Madhuri J, Smitha B, Sridhar S (2004) Dehydration of ethanol through blend membranes of chitosan and sodium alginate by pervaporation. Sep Purif Technol 40:259-266. https:// doi.org/10.1016/j.seppur.2004.03.003

Khoonsap S, Amnuaypanich S (2011) Mixed matrix membranes prepared from poly(vinyl alcohol) (PVA) incorporated with zeolite 4A-graft-poly(2-hydroxyethyl methacrylate) (zeolite-gPHEMA) for the pervaporation dehydration of water-acetone mixtures. J Membr Sci 367:182-189. https://doi.org/10.1016/j. memsci.2010.10.058

Lee YM (1993) Modified chitosan membranes for pervaporation. Desalination 90:277-290. https://doi. org/10.1016/0011-9164(93)80181-L

Lee YM, Shin EM (1991) Pervaporation separation of water-ethanol through modified chitosan membranes. IV. Phosphorylated chitosan membranes. J Membr Sci 64:145-152. https://doi. org/10.1016/0376-7388(91)80085-K
Lee YM, Nam SY, Kim JH (1992) Pervaporation of water-ethanol through poly(vinyl alcohol)/chitosan blend membrane. Polym Bull 29:423-429. https://doi.org/10.1007/BF00944840

Li J, Zhang G, Ji S, Wang N, An W (2012) Layerby-layer assembled nanohybrid multilayer membranes for pervaporation dehydration of acetone-water mixtures. J Membr Sci 415-416:745-757. https://doi.org/10.1016/j.memsci.2012.05.066

Moon GY, Pal R, Huang RYM (1999) Novel two-ply composite membranes of chitosan and sodium alginate for the pervaporation dehydration of isopropanol and ethanol. J Membr Sci 156:17-27. https://doi.org/10.1016/S0376-7388(98)00322-6

Ng LY, Mohammad AW, Leo CP, Hilal N (2013) Polymeric membranes incorporated with metal/metal oxide nanoparticles: a comprehensive review. Desalination 308:15-33. https://doi. org/10.1016/j.desal.2010.11.033

Nigiz FU, Hilmioglu ND (2013) Pervaporation of ethanol/water mixtures by zeolite filled sodium alginate membrane. Desalin Water Treat 51:637-643. https://doi.org/10.1080/19443994.2 012.714582

Ong YK, Shi GM, Le NL, Tang YP, Zuo J, Nunes SP, Chung T (2016) Recent membrane development for pervaporation processes. Progr Polym Sci 57:1-31. https://doi.org/10.1016/j. progpolymsci.2016.02.003

Pati SS, Gopinath S, Panneerselvam G, Antony MP, Philip J (2012) High temperature phase transformation studies in magnetite nanoparticles doped with $\mathrm{Co}^{2+}$ ion. J Appl Phys 112:054320. https://doi.org/10.1063/1.4748318

Premakshi HG, Ramesh K, Kariduraganavar MY (2015) Modification of crosslinked chitosan membrane using NaY zeolite for pervaporation separation of water-isopropanol mixtures. Chem Eng Res Des 94:32-43. https://doi.org/10.1016/j. cherd.2014.11.014

Rybak A, Dudek G, Krasowska M, Strzelewicz A, Grzywna ZJ, Sysel P (2014) Magnetic mixed matrix membranes in air separation. Chem Pap 68:1332-1340. https://doi.org/10.2478/s11696-014-0587-x

Sairam M, Patil MB, Verrapur RS, Patil SA, Aminabhavi TM (2006) Novel dense poly (vinyl alcohol) $-\mathrm{TiO}_{2}$ mixed matrix membranes for pervaporation separation of water-isopropanol mixtures at 30 C. J Membr Sci 281:95-102. https://doi.org/10.1016/j. memsci.2006.03.022

Sun H, Lu L, Chen X, Jiang Z (2008) Pervaporation dehydration of aqueous ethanol solution using H-ZSM-5 filled chitosan membranes. Sep Purif Technol 58:429-436. https://doi.org/10.1016/j. seppur.2007.09.012

Sunitha K, Satyanarayana SV, Sridhar S (2012) Phosphorylated chitosan membranes for the separation of ethanol-water mixtures by pervaporation. Carbohyd Polym 87:1569-1574. https://doi. org/10.1016/j.carbpol.2011.09.054

Tancharernrat T, Rempel GL, Prasassarakich P (2014) Preparation of styrene butadiene copolymer-of water-ethanol mixtures. Chem Eng J 258:290-300. https://doi.org/10.1016/j.cej.2014.05.151

Thamaphat K, Limsuwan P, Ngotawornchai B (2008) Phase Characterization of $\mathrm{TiO}_{2}$ Powder by XRD and TEM. Kasetsart J (Nat Sci) 42:357-361

Turczyn R, Gnus M, Dudek G, Tórz A, Łącka D, Strzelewicz A, Łapkowski M (2015) Vapour permeation study of water and ethanol through crosslinked chitosan and alginate membranes. PCACD 20:281-288. https://doi.org/10.15259/PCACD.20.28

Uragami T, Takigawa K (1990) Permeation and separation characteristics of ethanol-water mixtures through chitosan derivative membranes by pervaporation and evapomeation. Polymer 31:668-672. https://doi.org/10.1016/0032-3861(90)90287-9

Won JM, Bae SY, Ha BH, Kim HT, Kumazawa H (1996) Plasticization of chitosan membrane for pervaporation of aqueous ethanol solution. Korean J Chem Eng 13(3):324-327. https://doi.org/10.1007/ BF02705957 
Wu KC-W, Kang C-H, Lin YF, Tung KL, Deng Y-H, Ahamad T, Alshehri SM, Suzuki N, Yamauchi Y (2016) towards acidtolerated ethanol dehydration: chitosan-based mixed matrix membranes containing cyano-bridged coordination polymer nanoparticles. J Nanosci Nanotechnol 16:4141-4146. https://doi. org/10.1166/jnn.2016.12614

Xia L, Li C, Wang Y (2016) In-situ crosslinked PVA/organosilica hybrid membranes for pervaporation separations. J Membr Sci 498:263-275. https://doi.org/10.1016/j.memsci.2015.10.025

Yang D, Li J, Jiang Z, Lu L, Chen X (2009) Chitosan/TiO 2 nanocomposite pervaporation membranes for ethanol dehydration. Chem Eng Sci 64:3130-3137. https://doi.org/10.1016/j.ces.2009.03.042

Zhang W, Li GW, Fang YJ, Wang XP (2007) Maleic anhydride surface-modification of crosslinked chitosan membrane and its pervaporation performance. J Membr Sci 295:130-138. https://doi. org/10.1016/j.memsci.2007.03.001
Zhao CH, Jiang ZY, Zhao J, Cao KT, Zhang Q, Pan FS (2014) High pervaporation dehydration performance of the composite membrane with an ultrathin alginate/poly(acrylic acid)- $\mathrm{Fe}_{3} \mathrm{O}_{4}$ active layer. Ind Eng Chem Res 53:1606. https://doi.org/10.1021/ ie $403437 \mathrm{~g}$

Zhou C, Zhou J, Aisheng H (2016) Seeding-free synthesis of zeolite FAU membrane for seawater desalination by pervaporation. Microporous Mesoporous Mater 234:377-383. https://doi. org/10.1016/j.micromeso.2016.07.050

Zielińska K, Kujawski W, Chostenko AG (2011) Chitosan hydrogel membranes for pervaporative dehydration of alcohols. Sep Purif Technol 83:114-120. https://doi.org/10.1016/j. seppur.2011.09.023 